\title{
FAIRNESS AND INCENTIVES IN RELATION-BASED SOCIETIES ABSTRACT
}

This paper mainly discusses the effects of fairness on incentives in relation-based societies (e.g., China) through the principal-agent framework. Our analyses give the conditions under which the consideration of fairness will decrease or increase the agent's efficiency wage. At the same time, our analyses give the conditions under which taking into account fairness will make the principal's constraint to incentivize the agent easier or harder to be satisfied. In a word, this paper finds that the incentive effects of fairness are condition-dependent, and that moral hazard problems are more subtle and difficult to be tackled when fairness is taken into account.

Keywords: Fairness, Incentive, Principal-agent, Efficiency Wage

JEL Classification: A12, D63, J33

\section{INTRODUCTION}

More and more economists pay attention to the effects of fairness on economic relations. However, there are different definitions of fairness. In his original paper, Rabin (1993) develops a formal benchmark which incorporates fairness into game theory and economics. Rabin's fairness means that people like to help those who are helping them and hurt those who are hurting them. Zajac (1995) holds that "strategic uses of fairness to advance self-interest is commonplace," and that to develop a theory of fairness strategizing needs to incorporate two feathers of human behavior. The first feather is that people are not ususally energized by a sense of fairness but by a feeling of unfairness. The second feather is that "people have a marvelous ability to deny." Konow (1996) generalizes a conclusion from the empiricial research that "fairness is a highly differentiated phenomenon which varies widely with context, e.g. social, institutional or cultural context." Kaplow and Shavell (2002) are of the opinion that "notions of fairness typically are used to reach conclusions based upon situational characteristics of events." Alvi (1998) holds that there are three sources of fairness: moral precept, convention, and reciprocity. The first source means that "fairness is driven by moral prerogatives." The second source implies that "fairness is a stable convention brought

\footnotetext{
1 Associate Professor

Department of Economics, School of Business, Nanjing University, 22 Hankou Road, Nanjing 210093, P. R. China

Phone: $86-25-83621121(\mathrm{O})$

E-mail: jiancaipi@hotmail.com; pi2008@nju.edu.cn

Academic Degree: Ph.D. in Economics

Current Position: Associate Professor with Department of Economics, School of Business, Nanjing University

Homepage: http://nubs.nju.edu.cn/en/faculty.php/160

http://nubs.nju.edu.cn/faculty.php/160
} 
about by an evolutionary process." The third source signifies that fairness is the result of reciprocity. In a word, different people hold dissimilar and even conflicting ideas about fairness. In order to unify some concepts in the existent theories of fairness, Corchón and Iturbe-Ormaetxe (2001) try to propose a procedure based on the aspiration functions, which represents an important direction and a potential mathematical framework for the future research.

Although many mathematical tools are used to handle fairness, such as game theory (Rabin, 1993; Morelli and Sacco, 1997; Cox et al., 2007), bargaining theory (Bereby-Meyer and Niederle, 2005; von Siemens, 2009), and incentive theory (Fehr and Schmidt, 2000; Fehr and Schmidt, 2004; Fehr et al., 2007), there are three very distinct approaches among them. The first approach is to regard fairness as a variable of the utility function (e.g., Fehr and Schmidt, 1999; Bolton and Ockenfels, 2000; Trautmann, 2009). These seminal works have made a great progress in incorporating fairness into formal analyses, although they apply different processing methods, which makes it easy for them to make some specific predictions about many phenomena. The second approach is to treat fairness as a an extrinsic constraint (e.g., $\mathrm{Pi}, 2007,2008)$. This approach argues that fairness is a psychological factor which is determined by the cultural background and special situation to a great extent (Kahneman et al., 1986; Akerlof and Yellen, 1988; Konow, 1996; Shavell, 2002), and can conduct formal mathematical analyses easily by introducing some constraint conditions. The third approach is to introduce the psychological cost or painful guilt resulting from unfairness (e.g., Gill and Stone, 2010). People can easily understand this approach by intuition. As a whole, our paper will adopt the third approach.

There are two papers which are closely related to our paper. Fehr and Schmidt (2000) and Fehr et al. (2007) also examine fairness in strategic interactions, and find that fairness concerns can affect the provision of incentives through different contracts. There are three important distinctions between our paper and theirs. Firstly, their models adopt the first approach to some extent, while our model adopts the third approach in the mass. Thus, our main variables are fundamentally different from theirs. Secondly, their models are more simplified and focuses mainly on the choice of contracts, while our model is more complex and focuses mainly on the different equilibrium outcomes without and with fairness. Thirdly, our analyses are on the basis of relation-based societies (e.g., China). In relation-based societies, relation (or guanxi in Chinese language) is an important factor that should be considered. In these kinds of societies, the principal and the agent are thoroughly familiar with each other. In other words, the principal has intimate knowledge of the agent, and the agent does so, too. This relation or guanxi can ensure that they have common knowledge about cost parameters related to unfairness through repeated social interactions. Furthermore, the existent literature shows that small group sizes more favor fairness (Höffler, 1999).

The rest of the paper is organized as follows. Section 2 is the basic setup. Section 3 provides the model without fairness. Section 4 offers the model with fairness. Section 5 conducts a comparative analysis of outcomes derived from the two different models. Some concluding remarks are made in Section 6.

\section{THE BASIC SETUP}

In this section, we follow Laffont and Martimort's (2002) analytical framework. There is a principal-agent relationship which is subject to moral hazard. It is assumed that the agent is 
risk-neutral. If he exerts effort level $e \in\{0,1\}$, the principal's added-value will be $\bar{V}$ with probability $\pi(e)$, and $\underline{V}$ with probability $1-\pi(e)$, where $0<\pi(e)<1 . \pi(e)$ and $1-\pi(e)$ can be seen as success and failure probabilities, respectively. When the agent's performance is good, he can get a bonus; however, when his performance is bad, he will not be punished. That is to say, he is protected by limited liability. When he exerts no effort, his effort cost is $\Psi_{0}=0$. When he exerts effort, his effort cost is $\Psi_{1}=\Psi>0$. The subscripts 0 and 1 represent $e=0$ and $e=1$, respectively. For the sake of narrative simplicity, we call $\Psi$ the exertion cost. The following mathematical definitions should be noted, $\pi(1)=\pi_{1}$, $\pi(0)=\pi_{0}, \Delta \pi=\pi_{1}-\pi_{0}>0, \Delta V=\bar{V}-\underline{V}>0$.

In order to overcome the moral hazard problem, the principal has to adopt an appropriate scheme to incentivize the agent. When the added-value is $\bar{V}$, the principal offers an efficiency wage $\bar{w} \geq 0$ to the agent. However, when the added-value is $\underline{V}$, the principal offers an efficiency wage $\underline{w} \geq 0$ to the agent. It is assumed that $\bar{w} \geq \underline{w}$.

We consider two distinct cases in this paper. The first case is that the principal and the agent do not care for fairness. This case is the same as that in the standard incentive theory. The second case is that the principal and the agent take fairness into account. This case is greatly different from that of the traditional literature. If the agent exerts effort and succeeds, both the principal and the agent will take it as fair. However, if the agent exerts effort and fails, both the principal and the agent will take it as unfair, which will bring unfairness costs $F_{h} \geq 0$ and $f_{h} \geq 0$ to the principal and the agent, respectively. Similarly, if the agent exerts no effort and succeeds, both the principal and the agent will take it as unfair, which will bring unfairness costs $F_{b} \geq 0$ and $f_{b} \geq 0$ to the principal and the agent, respectively. Unfairness related to $F_{h}$ and $f_{h}$ is called the first-type unfairness, and hence $F_{h}$ and $f_{h}$ are called the first-type unfairness cost to the principal and the agent, respectively. Similarly, unfairness related to $F_{b}$ and $f_{b}$ is called the second-type unfairness, and hence $F_{b}$ and $f_{b}$ are called the second-type unfairness cost to the principal and the agent, respectively. Unfairness leads to some kind of disutility cost to the principal and the agent who receive this kind of feeling.

The introduction of $F_{h}, f_{h}, F_{b}$ and $f_{b}$ is inspired by Gill and Stone (2010), who treat the unfairness in an indirect way by introducing some ad hoc cost parameters which are different from ours because they deal with a dissimilar issue. Here, the relationship between $f_{h}$ and $f_{b}$ should be noted. $f_{h}$ and $f_{b}$ reflect the agent's degree of psychological hatred 
to "reaping where one has not sown" (laoerbuhuo in Chinese language) and "getting something for nothing" (bulaoerhuo in Chinese language) in relation-based societies (e.g., China), respectively. So, the relation may be that $f_{h}>f_{b}, f_{h}<f_{b}$ and $f_{h}=f_{b}$, which is obviously ambiguous. Similarly, the relation between $F_{h}$ and $F_{b}$ is uncertain, too.

The timing of the principal-agent game is as follows.

(1) At $t=0$, the principal offers an incentive contract $\{(\underline{w}, \bar{w})\}$ to the agent.

(2) At $t=1$, the agent rejects or accepts the offer.

(3) At $t=2$, the agent chooses an effort, which is equal to 1 or 0.

(4) At $t=3$, the principal's added-value is realized.

(5) At $t=4$, the signed contract is enforced.

\section{THE MODEL WITHOUT FAIRNESS}

When the principal and the agent do not consider fairness, there is no unfairness cost at all. In order to make the agent exert effort, the principal must find an optimal compensation plan $\{(\underline{w}, \bar{w})\}$. The principal's programming problem will be:

$$
\begin{array}{ll}
\max _{\{(\underline{w}, \bar{w})\}} & \pi_{1}(\bar{V}-\bar{w})+\left(1-\pi_{1}\right)(\underline{V}-\underline{w}) \\
\text { s.t. } & \pi_{1} \bar{w}+\left(1-\pi_{1}\right) \underline{w}-\Psi \geq \pi_{0} \bar{w}+\left(1-\pi_{0}\right) \underline{w} \\
& \pi_{1} \bar{w}+\left(1-\pi_{1}\right) \underline{w}-\Psi \geq 0 \\
& \underline{w} \geq 0
\end{array}
$$

(1), (2), and (3) are the agent's incentive compatibility, participation, and limited liability constraints when fairness is not considered, respectively.

According to the standard incentive theory, it is easy for us to find that constraints (1) and (3) are binding.

Solving this programming problem, we obtain:

$$
\begin{aligned}
& \underline{w}^{N^{*}}=0 \\
& \bar{w}^{N^{*}}=\frac{\Psi}{\Delta \pi}
\end{aligned}
$$

The superscript $N^{*}$ stands for second-best state with no consideration of fairness. $\bar{w}^{N *}$ is the agent's efficiency wage with no consideration of fairness.

In addition, we need to consider the principal's constraint to incentivize the agent:

$$
\pi_{1}\left(\bar{V}-\frac{\Psi}{\Delta \pi}\right)+\left(1-\pi_{1}\right) \underline{V} \geq \pi_{0} \bar{V}+\left(1-\pi_{0}\right) \underline{V}
$$

It is quite obvious that (6) can be simplified into:

$$
\Delta \pi \Delta V \geq \frac{\pi_{1} \Psi}{\Delta \pi}
$$

Only when (7) is satisfied does the principal have the incentive to make the agent exert 
effort, otherwise he will prefer not to do it. Therefore, this constraint should be taken seriously during the course of our analyses.

\section{THE MODEL WITH FAIRNESS}

When the principal and the agent do consider fairness, the unfairness costs should not be neglected. In this case, the principal's new programming problem will become:

$$
\begin{array}{ll}
\max _{\{\underline{(}, \bar{w})\}} & \pi_{1}(\bar{V}-\bar{w})+\left(1-\pi_{1}\right)\left(\underline{V}-\underline{w}-F_{h}\right) \\
\text { s.t. } & \pi_{1} \bar{w}+\left(1-\pi_{1}\right)\left(\underline{w}-f_{h}\right)-\Psi \geq \pi_{0}\left(\bar{w}-f_{b}\right)+\left(1-\pi_{0}\right) \underline{w} \\
& \pi_{1} \bar{w}+\left(1-\pi_{1}\right)\left(\underline{w}-f_{h}\right)-\Psi \geq 0 \\
& \underline{w} \geq 0
\end{array}
$$

(8), (9), and (10) are the agent's incentive compatibility, participation, and limited liability constraints when fairness is considered, respectively.

Two irrelevant constraints have been neglected and omitted. For the sake of analytical simplicity, we assume that $f_{b} \leq \min \left\{\frac{\Psi+\left(1-\pi_{1}\right) f_{h}-\pi_{0} f_{b}}{\Delta \pi}, \frac{\Psi+\left(1-\pi_{1}\right) f_{h}}{\pi_{1}}\right\} \quad$ or

$$
\min \left\{\frac{\Psi+\left(1-\pi_{1}\right) f_{h}-\pi_{0} f_{b}}{\Delta \pi}, \frac{\Psi+\left(1-\pi_{1}\right) f_{h}}{\pi_{1}}\right\}<f_{b} \leq \max \left\{\frac{\Psi+\left(1-\pi_{1}\right) f_{h}-\pi_{0} f_{b}}{\Delta \pi}, \frac{\Psi+\left(1-\pi_{1}\right) f_{h}}{\pi_{1}}\right\}
$$

which can ensure that the agent's participation constraint when he exerts no effort (namely, $\left.\pi_{0}\left(\bar{w}-f_{b}\right)+\left(1-\pi_{0}\right) \underline{w} \geq 0\right)$ will always be satisfied. That is to say, this constraint is irrelevant.

According to the standard incentive theory, it is easy for us to find that constraint (10) is binding and that constraint (8) is binding when $\Psi \geq \pi_{1} f_{b}-\left(1-\pi_{1}\right) f_{h}$, and that constraint (9) is binding when $\Psi<\pi_{1} f_{b}-\left(1-\pi_{1}\right) f_{h}$.

Solving this new programming problem, we obtain:

If $\Psi \geq \pi_{1} f_{b}-\left(1-\pi_{1}\right) f_{h}$, then

$$
\begin{aligned}
& \underline{w}^{F^{*}}=0 \\
& \bar{w}^{F^{*}}=\frac{\Psi+\left(1-\pi_{1}\right) f_{h}-\pi_{0} f_{b}}{\Delta \pi}
\end{aligned}
$$

If $\Psi<\pi_{1} f_{b}-\left(1-\pi_{1}\right) f_{h}$, then

$$
\begin{aligned}
& \underline{w}^{F^{*}}=0 \\
& \bar{w}^{F^{*}}=\frac{\Psi+\left(1-\pi_{1}\right) f_{h}}{\pi_{1}}
\end{aligned}
$$


The superscript $F^{*}$ stands for second-best state with the consideration of fairness. $\bar{w}^{F^{*}}$ is the agent's efficiency wage with the consideration of fairness.

If $\Psi \geq \pi_{1} f_{b}-\left(1-\pi_{1}\right) f_{h}$, then the principal's constraint to incentivize the agent will be:

$$
\begin{aligned}
& \pi_{1}\left(\bar{V}-\frac{\Psi+\left(1-\pi_{1}\right) f_{h}-\pi_{0} f_{b}}{\Delta \pi}\right)+\left(1-\pi_{1}\right)\left(\underline{V}-F_{h}\right) \\
& \geq \pi_{0}\left(\bar{V}-F_{b}\right)+\left(1-\pi_{0}\right) \underline{V}
\end{aligned}
$$

It is quite obvious that (15) can be simplified into:

$$
\Delta \pi \Delta V \geq \frac{\pi_{1}\left[\Psi+\left(1-\pi_{1}\right) f_{h}-\pi_{0} f_{b}\right]}{\Delta \pi}+\left(1-\pi_{1}\right) F_{h}-\pi_{0} F_{b}
$$

If $\Psi<\pi_{1} f_{b}-\left(1-\pi_{1}\right) f_{h}$, then the principal's constraint to incentivize the agent will be:

$$
\begin{aligned}
& \pi_{1}\left[\bar{V}-\frac{\Psi+\left(1-\pi_{1}\right) f_{h}}{\pi_{1}}\right]+\left(1-\pi_{1}\right)\left(\underline{V}-F_{h}\right) \\
& \geq \pi_{0}\left(\bar{V}-F_{b}\right)+\left(1-\pi_{0}\right) \underline{V}
\end{aligned}
$$

It is quite obvious that (17) can be simplified into:

$$
\Delta \pi \Delta V \geq \Psi+\left(1-\pi_{1}\right)\left(f_{h}+F_{h}\right)-\pi_{0} F_{b}
$$

The implications of (16) and (18) are similar to that of (7) which has been stressed in Section 3.

\section{A COMPARATIVE ANALYSIS}

In this section, we will conduct a comparative analysis between the outcome without the consideration of fairness and that with the consideration of fairness. By comparison, it is easy for us to obtain the following four propositions.

Proposition 1: When $\Psi \geq \pi_{1} f_{b}-\left(1-\pi_{1}\right) f_{h}$, if $f_{h}<\frac{\pi_{0} f_{b}}{1-\pi_{1}}$, then taking into account fairness will decrease the agent's efficiency wage; if $f_{h} \geq \frac{\pi_{0} f_{b}}{1-\pi_{1}}$, then taking into account fairness will increase the agent's efficiency wage.

Proof: If $\Psi \geq \pi_{1} f_{b}-\left(1-\pi_{1}\right) f_{h}$ and $f_{h}<\frac{\pi_{0} f_{b}}{1-\pi_{1}}$, then from (5) and (12), we obtain:

$$
\bar{w}^{N^{*}}-\bar{w}^{F^{*}}=\frac{\Psi}{\Delta \pi}-\frac{\Psi+\left(1-\pi_{1}\right) f_{h}-\pi_{0} f_{b}}{\Delta \pi}=-\frac{1-\pi_{1}}{\Delta \pi}\left(f_{h}-\frac{\pi_{0} f_{b}}{1-\pi_{1}}\right)>0 .
$$

If $\Psi \geq \pi_{1} f_{b}-\left(1-\pi_{1}\right) f_{h}$ and $f_{h} \geq \frac{\pi_{0} f_{b}}{1-\pi_{1}}$, then from (5) and (12), we obtain: 


$$
\bar{w}^{N^{*}}-\bar{w}^{F^{*}}=\frac{\Psi}{\Delta \pi}-\frac{\Psi+\left(1-\pi_{1}\right) f_{h}-\pi_{0} f_{b}}{\Delta \pi}=-\frac{1-\pi_{1}}{\Delta \pi}\left(f_{h}-\frac{\pi_{0} f_{b}}{1-\pi_{1}}\right) \leq 0 .
$$

Proposition 1 implies that when the exertion cost is large enough and the the first-type unfairness cost to the agent is small enough, the consideration of fairness will decrease the agent's efficiency wage, and that when the exertion cost and the the first-type unfairness cost to the agent are both large enough, the consideration of fairness will increase the agent's efficiency wage.

Proposition 2: When $\Psi<\pi_{1} f_{b}-\left(1-\pi_{1}\right) f_{h}$, if $\Psi \geq \frac{\Delta \pi\left(1-\pi_{1}\right) f_{h}}{\pi_{0}}$, then taking into account fairness will decrease the agent's efficiency wage; if $\Psi<\frac{\Delta \pi\left(1-\pi_{1}\right) f_{h}}{\pi_{0}}$, then taking into account fairness will increase the agent's efficiency wage.

Proof: If $\Psi<\pi_{1} f_{b}-\left(1-\pi_{1}\right) f_{h}$ and $\Psi \geq \frac{\Delta \pi\left(1-\pi_{1}\right) f_{h}}{\pi_{0}}$, then from (5) and (14), we obtain:

$$
\bar{w}^{N^{*}}-\bar{w}^{F^{*}}=\frac{\Psi}{\Delta \pi}-\frac{\Psi+\left(1-\pi_{1}\right) f_{h}}{\pi_{1}}=\frac{\pi_{0}}{\Delta \pi \pi_{1}}\left[\Psi-\frac{\Delta \pi\left(1-\pi_{1}\right) f_{h}}{\pi_{0}}\right] \geq 0
$$

If $\Psi<\pi_{1} f_{b}-\left(1-\pi_{1}\right) f_{h}$ and $\Psi<\frac{\Delta \pi\left(1-\pi_{1}\right) f_{h}}{\pi_{0}}$, then from (5) and (14), we obtain:

$$
\bar{w}^{N^{*}}-\bar{w}^{F^{*}}=\frac{\Psi}{\Delta \pi}-\frac{\Psi+\left(1-\pi_{1}\right) f_{h}}{\pi_{1}}=\frac{\pi_{0}}{\Delta \pi \pi_{1}}\left[\Psi-\frac{\Delta \pi\left(1-\pi_{1}\right) f_{h}}{\pi_{0}}\right]<0 .
$$

Proposition 2 implies that when the exertion cost is moderate, the consideration of fairness will decrease the agent's efficiency wage, and that when the exertion cost is small enough, the consideration of fairness will increase the agent's efficiency wage.

Proposition 3: Taking into account fairness will make the principal's constraint to incentivize the agent easier to be satisfied when $\Psi \geq \pi_{1} f_{b}-\left(1-\pi_{1}\right) f_{h}$ and $f_{h} \geq \frac{\pi_{0} \Delta \pi F_{b}-\left(1-\pi_{1}\right) \Delta \pi F_{h}+\pi_{0} \pi_{1} f_{b}}{\pi_{1}\left(1-\pi_{1}\right)} \quad$ or $\quad$ when $\quad \Psi<\pi_{1} f_{b}-\left(1-\pi_{1}\right) f_{h} \quad$ and $\Psi \leq \frac{\Delta \pi\left(1-\pi_{1}\right)\left(f_{h}+F_{h}\right)}{\pi_{0}}-\Delta \pi F_{b}$

Proof: When $\Psi \geq \pi_{1} f_{b}-\left(1-\pi_{1}\right) f_{h}$ and $f_{h} \geq \frac{\pi_{0} \Delta \pi F_{b}-\left(1-\pi_{1}\right) \Delta \pi F_{h}+\pi_{0} \pi_{1} f_{b}}{\pi_{1}\left(1-\pi_{1}\right)}$, then from (7) and (16), we obtain:

$$
\begin{aligned}
& \frac{\pi_{1} \Psi}{\Delta \pi}-\left\{\frac{\pi_{1}\left[\Psi+\left(1-\pi_{1}\right) f_{h}-\pi_{0} f_{b}\right]}{\Delta \pi}+\left(1-\pi_{1}\right) F_{h}-\pi_{0} F_{b}\right\} \\
& =-\frac{\pi_{1}\left[\left(1-\pi_{1}\right) f_{h}-\pi_{0} f_{b}\right]}{\Delta \pi}-\left(1-\pi_{1}\right) F_{h}+\pi_{0} F_{b}
\end{aligned}
$$




$$
=-\frac{\pi_{1}\left(1-\pi_{1}\right)}{\Delta \pi}\left[f_{h}-\frac{\pi_{0} \Delta \pi F_{b}-\left(1-\pi_{1}\right) \Delta \pi F_{h}+\pi_{0} \pi_{1} f_{b}}{\pi_{1}\left(1-\pi_{1}\right)}\right] \leq 0 .
$$

When $\Psi<\pi_{1} f_{b}-\left(1-\pi_{1}\right) f_{h}$ and $\Psi \leq \frac{\Delta \pi\left(1-\pi_{1}\right)\left(f_{h}+F_{h}\right)}{\pi_{0}}-\Delta \pi F_{b}$, then from (7) and (18), we obtain:

$$
\begin{aligned}
& \frac{\pi_{1} \Psi}{\Delta \pi}-\left[\Psi+\left(1-\pi_{1}\right)\left(f_{h}+F_{h}\right)-\pi_{0} F_{b}\right] \\
& =\frac{\pi_{0}}{\Delta \pi}\left\{\Psi-\left[\frac{\Delta \pi\left(1-\pi_{1}\right)\left(f_{h}+F_{h}\right)}{\pi_{0}}-\Delta \pi F_{b}\right]\right\} \leq 0 .
\end{aligned}
$$

Proposition 3 implies that when the exertion cost and and the first-type unfairness cost to the agent are both large enough, the principal is more likely to incentivize the agent, and that when the exertion cost is small enough, the principal is more likely to incentivize the agent.

Proposition 4: Taking into account fairness will make the principal's constraint to incentivize the agent harder to be satisfied when $\Psi \geq \pi_{1} f_{b}-\left(1-\pi_{1}\right) f_{h}$ and

$$
\begin{aligned}
& f_{h}<\frac{\pi_{0} \Delta \pi F_{b}-\left(1-\pi_{1}\right) \Delta \pi F_{h}+\pi_{0} \pi_{1} f_{b}}{\pi_{1}\left(1-\pi_{1}\right)} \quad \text { or } \quad \text { when } \quad \Psi<\pi_{1} f_{b}-\left(1-\pi_{1}\right) f_{h} \quad \text { and } \\
& \Psi>\frac{\Delta \pi\left(1-\pi_{1}\right)\left(f_{h}+F_{h}\right)}{\pi_{0}}-\Delta \pi F_{b} .
\end{aligned}
$$

Proof: When $\Psi \geq \pi_{1} f_{b}-\left(1-\pi_{1}\right) f_{h}$ and $f_{h}<\frac{\pi_{0} \Delta \pi F_{b}-\left(1-\pi_{1}\right) \Delta \pi F_{h}+\pi_{0} \pi_{1} f_{b}}{\pi_{1}\left(1-\pi_{1}\right)}$, then from (7) and (16), we obtain:

$$
\begin{aligned}
& \frac{\pi_{1} \Psi}{\Delta \pi}-\left\{\frac{\pi_{1}\left[\Psi+\left(1-\pi_{1}\right) f_{h}-\pi_{0} f_{b}\right]}{\Delta \pi}+\left(1-\pi_{1}\right) F_{h}-\pi_{0} F_{b}\right\} \\
& =-\frac{\pi_{1}\left[\left(1-\pi_{1}\right) f_{h}-\pi_{0} f_{b}\right]}{\Delta \pi}-\left(1-\pi_{1}\right) F_{h}+\pi_{0} F_{b} \\
& =-\frac{\pi_{1}\left(1-\pi_{1}\right)}{\Delta \pi}\left[f_{h}-\frac{\pi_{0} \Delta \pi F_{b}-\left(1-\pi_{1}\right) \Delta \pi F_{h}+\pi_{0} \pi_{1} f_{b}}{\pi_{1}\left(1-\pi_{1}\right)}\right]>0 .
\end{aligned}
$$

When $\Psi<\pi_{1} f_{b}-\left(1-\pi_{1}\right) f_{h}$ and $\Psi>\frac{\Delta \pi\left(1-\pi_{1}\right)\left(f_{h}+F_{h}\right)}{\pi_{0}}-\Delta \pi F_{b}$, then from (7) and (18), we obtain:

$$
\begin{aligned}
& \frac{\pi_{1} \Psi}{\Delta \pi}-\left[\Psi+\left(1-\pi_{1}\right)\left(f_{h}+F_{h}\right)-\pi_{0} F_{b}\right] \\
& =\frac{\pi_{0}}{\Delta \pi}\left\{\Psi-\left[\frac{\Delta \pi\left(1-\pi_{1}\right)\left(f_{h}+F_{h}\right)}{\pi_{0}}-\Delta \pi F_{b}\right]\right\}>0 .
\end{aligned}
$$

Proposition 4 implies that when the exertion cost is large enough and the the first-type unfairness cost to the agent is small enough, the principal is more unlikely to incentivize the agent, and that when the exertion cost is moderate, the principal is more unlikely to 
incentivize the agent.

There is a extreme case that should be stressed and discussed. The case is that there don't exist the second-type unfairness costs at all. That is to say $F_{b}=f_{b}=0$. This special case can act as a benchmark that sets a starting point for our analyses. According to Propositions 1-4, we can find that in this case: (a) $\Psi \geq \pi_{1} f_{b}-\left(1-\pi_{1}\right) f_{h}$ (namely, $\Psi \geq-\left(1-\pi_{1}\right) f_{h}$ ) and $f_{h} \geq \frac{\pi_{0} f_{b}}{1-\pi_{1}}$ (namely, $f_{h} \geq 0$ ), and (b) $\Psi \geq \pi_{1} f_{b}-\left(1-\pi_{1}\right) f_{h}$ (namely, $\Psi \geq-\left(1-\pi_{1}\right) f_{h}$ ) and $f_{h} \geq \frac{\pi_{0} \Delta \pi F_{b}-\left(1-\pi_{1}\right) \Delta \pi F_{h}+\pi_{0} \pi_{1} f_{b}}{\pi_{1}\left(1-\pi_{1}\right)}$ (namely, $\left.f_{h} \geq-\frac{\Delta \pi F_{h}}{\pi_{1}}\right)$. (a) and (b) imply that taking into account fairness will increase the agent's efficiency wage and make the principal's constraint to incentivize the agent easier to be satisfied.

\section{CONCLUDING REMARKS}

In this paper, we mainly discuss the effects of fairness on incentives in relation-based societies (e.g., China) through the improved principal-agent framework. Our analyses show that under some conditions the consideration of fairness will decrease the agent's efficiency wage, while under other conditions the consideration of fairness will increase the agent's efficiency wage. At the same time, our analyses show that under some conditions taking into account fairness will make the principal's constraint to incentivize the agent easier to be satisfied, while under other conditions taking into account fairness will make the principal's constraint to incentivize the agent harder to be satisfied. In summary, fairness concerns play an important role in economic relations in relation-based societies, and moral hazard problems are more subtle and difficult to be tackled when fairness is taken into account.

\section{REFERENCES}

Akerlof, G. A., Yellen, J. L., (1988), "Fairness and Unemployment", American Economic Review, Papers and Proceedings, 78(2): 44-49.

Alvi, E., (1998), "Fairness and Self-Interest: An Assessment", Journal of Socio-Economics, 27(2): 245-261.

Bereby-Meyer, Y., Niederle, M., (2005), "Fairness in Bargaining", Journal of Economic Behavior and Organization, 56(2): 173-186.

Bolton, G., Ockenfels, A., (2000), "ERC: A Theory of Equity, Reciprocity, and Competition”, American Economic Review, 90(1): 166-193.

Corchón, L. C., Iturbe-Ormaetxe, I., (2001), “A Proposal to Unify Some Concepts in the Theory of Fairness", Journal of Economic Theory, 101(2): 540-571.

Cox, J. C., Friedman, D., Gjerstad, S., (2007), "A Tractable Model of Reciprocity and Fairness", Games and Economic Behavior, 59(1): 17-45.

Fehr, E., Klein, A., Schmidt, K. M., (2007), "Fairness and Contract Design", Econometrica, 75(1): 121-154.

Fehr, E., Schmidt, K. M., (1999), “A Theory of Fairness, Competition and Cooperation”, 
Quarterly Journal of Economics, 114(3): 817-868.

Fehr, E., Schmidt, K. M., (2000), "Fairness, Incentives, and Contractual Choices", European Economic Review, 44(4-6): 1057-1068.

Fehr, E., Schmidt, K. M., (2004), "Fairness and Incentives in a Multi-Task Principal-Agent Model", Scandinavian Journal of Economics, 106(3): 453-474.

Gill, D., Stone, R., (2010), "Fairness and Desert in Tournaments", Games and Economic Behavior, 69(2): 346-364.

Höffler, F., (1999), “Some Play Fair, Some Don't: Reciprocal Fairness in a Stylized Principal - Agent Problem", Journal of Economic Behavior and Organization, 38(1): 113-131.

Kaplow, L., Shavell, S., (2002), Fairness and Welfare, (Cambridge, Massachusetts: Harvard University Press).

Kahneman, D., Knetsch, J., Thaler, R., (1986), "Fairness as a Constraint on Profit-Seeking: Entitlements in the Market", American Economic Review, 76(4): 728-741.

Konow, J., (1996), "A Positive Theory of Economic Fairness", Journal of Economic Behavior and Organization, 31(1): 13-35.

Laffont, J.-J., Martimort, D., (2002), The Theory of Incentives, (New Jersey: Princeton University Press).

Morelli, M., Sacco, P. L., (1997), "Game-Theoretic Definitions of Fairness and the Contractualistic Foundations of Justice”, Research in Economics, 51(4): 387-400.

Pi, J., (2007), "Fairness Compatibility Constraints and Collective Actions", Frontiers of Economics in China, 2(4): 644-652.

Pi, J., (2008), "Fairness as a Constraint", Humanomics, 24(3): 239-243.

Rabin, M., (1993), "Incorporating Fairness into Game Theory and Economics", American Economic Review, 83(5): 1281-1302.

von Siemens, F. A., (2009), "Bargaining under Incomplete Information, Fairness, and the Hold-Up Problem”, Journal of Economic Behavior and Organization, 71(2): 486-494.

Trautmann, S. T., (2009), “A Tractable Model of Process Fairness under Risk", Journal of Economic Psychology, 30(5): 803-813.

Zajac, E. E., (1995), Political Economy of Fairness, (Cambridge, Massachusetts: MIT Press).

\section{PRAVEDNOST I POTICAJI U DRUŠTVIMA ZASNOVANIMA NA RODBINSKIM VEZAMA}

\section{SAŽETAK}

Rad uglavnom razmatra učinke pravednosti na poticaje u društvima zasnovanima na rodbinskim vezama (npr. Kina) u okviru odnosa principala $i$ agenta. Naše analize prezentiraju uvjete pod kojima će razmatranje pravednosti smanjiti ili povećati agentovu stimulativnu nadnicu. Istovremeno, istraživanje prezentira uvjete pod kojima će uzimanje pravednosti u obzir otežati ili olakšati zadovoljavanje principalovih ograničenja pri poticanju agenta. Jednom rječju, ovaj rad pokazuje da poticajni učinci pravednosti ovise o okolnostima a da moralni problemi postaju istančaniji i teže rješivi kad se pravednost uzme u obzir.

Ključne riječi: pravednost, poticaj, principal-agent, stimulativna nadnica 